\title{
LARVAL BIOLOGY OF SIX FILARIAE OF THE SUB-FAMILY ONCHOCERCINAE IN A VERTEBRATE HOST
}

\author{
BAIN O.*, WANJI S.*, VUONG P. N. **, MARÉCHAL P.., LE GOFF L.*, PETIT G.* \\ With the technical assistance of S. PLATEAUX*, E. DUMARQUEZ ${ }^{* * *}$ and F. CHRÉTIEN"***
}

\section{Summary :}

The development of six filariae of the sub-family Onchocercinae Litomosoides sigmodontis, Acanthocheilonema viteae, Molinema dessetae, Monanema martini, Brugia malayi, B. pahangi-was compared in rodents, following a single inoculation of a low or high dose of infective larvae. Analysis was done with 105 rodents dissected and 53 rodents fixed for histopathology.

The percentage of larvae which developed corresponded to the proportion of those which were able to penetrate into the sub-cutaneous lymphatic vessels; this percentage was determined during the first day (phase 1) and was characteristic of the filaria-host pair, and independent of the number of larvae inoculated. It could remain stable for a long time, more than eight months with $M$. martini (phase 2); the phenomena of regulation appeared later (phase 3).

The larvae migrated through the lymphatic system, which represents a medium less protected and thus less agressive than the blood system. The coelomic cavities, almost devoid of inflammatory cells, represented an ultimate shelter, as well as the joint-cavities (colonized by some Dirofilariinae). Localizations in the cardio-pulmonary blood system were accidental and occurred when, during the migrations, some larvae penetrated into the thoracic channel and arrived in the superior vena cava, then the right ventricle and the pulmonary arteries (the biology of Dirofilaria immitis resulted in a secondary adaptation); such accidents may occur with adult filariae, especially. after drug treatment. One may expect similar events in human filariasis. These "occult" filariae, more frequent than it is usually thought, influence the immunological status and the pathology.

KEY WORDS : recovery rate, filarial migration. Iymphatic system. occult filariae. pulmonary pathology. human filariases.

\section{INTRODUCTION}

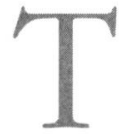

he larval biology of filariae obviously cannot be elucidated in humans. However, by multiplying the observations of various filariae in small rodents, several rules arise, so general, that it seems rational to presume their validity in human filariases.

"Laboratoire de Biologie Parasitaire, Protistologie, Helminthologie, URA 114 associée au CNRS, 61 rue Buffon, F75231 Paris Cedex 05.

*** Anatomie et Cytologie Pathologiques, 20 Avenue de la Gare, F91570 Bièvres.

**** Service Commun Animalerie, Faculté de Pharmacie, Université Paris-Sud, F92290 Châtenay-Malabry.

(1) This investigation was supported by the Science and Technology for Development Programme of the European Community, Contract No TS3-CT980037.
Résumé : Biologie larvaire de Six filaires OnCHOCERCINAE CHez L'HÖTE VERTÉBRÉ

Le développement de six filaires Onchocercinae - Litomosoides sigmodontis, Acanthocheilonema viteae, Molinema dessetae, Monanema martini, Brugia malayi, B. pahangi - est comparé chez le rongeur, inoculé par une petite ou une forte dose de larves infectantes. L'analyse est effectuée par dissection et histo-pathologie (respectivement 105 et 53 rongeurs).

Le pourcentage de larves qui se développe correspond à la proportion de celles qui pénètrent dans les vaisseaux lymphatiques souscutanés et échappent ainsi à la réaction inflammatoire; ce pourcentage est déterminé dès le premier jour (phase 1) et est caractéristique du couple filaire-hôte, indépendant du nombre de larves inoculées. Il peut rester stable longtemps, plus de huit mois chez $M$. martini (phase 2); les phénomènes de régulation apparaissent ultérieurement (phase 3).

Les larves migrent par le système lymphatique, qui représente un milieu moins bien protégé et donc moins agressif que le système sanguin; les cavités coelomiques, presque dépourvues d'éléments inflammatoires, représentent un ultime abri, de même que les cavités articulaires (colonisées par des Dirofilariinae). Les localisations dans le système circulatoire sanguin cardio-pulmonaire sont accidentelles: au cours des migrations, certaines larves s'engagent dans le canal thoracique et arrivent ainsi dans la veine cave supérieure, le coeur droit puis les artères pulmonaires lla biologie de Dirofilaria immitis résulte d'une adaptation secondaire); ces accidents peuvent se produire aussi chez les filaires adultes, particulièrement à la suite de traitements. Il faut s'attendre à des évènements semblables dans les filarioses humaines. Les filaires "occultes", plus nombreuses qu'on ne le pense, influent sur l'état immunitaire et sur la pathologie.

MOTS CLES : rendement. migrations larvaires, système lymphatique. filaires occultes. pathologie pulmonaire. filarioses humaines.

Six species of Onchocercinae were studied. The experiments were performed using similar procedures to allow comparisons. By a double analysis - dissection of rodents and histopathology- we tried to determine the quantitative relationships between larvae inoculated and filariae recovered, and to follow the migrations.

\section{MATERIALS AND METHODS}

FILARIAL SPECIES

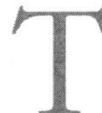
he filarial species are listed following the key of Anderson \& Bain (1976) with, for each species, the rodent host used, the adult worm localisation and 
the main references on the development in the susceptible hosts (Ref.) :

Litomosoides sigmodontis Chandler, 1931: Meriones unguiculatus (jird), pleural cavity, abdominal cavity. Ref : Scott, 1946; Cross \& Scott, 1947; Kershaw, 1953; Scott \& McDonald, 1953; Bertram, 1966; Wenk, 1967; Wenk \& Mössinger, 1991.

Acanthocheilonema viteae (Krepkogorskaya, 1933) : $M$. unguiculatus, muscular aponeuroses, peritoneal cavity, nervous system. Ref : Baltazard, Chabaud \& Minou, 1952; Chabaud, 1954; Weinstein \& Highman, 1974; Johnson et al., 1974; Neilson \& Forrester, 1975; Simpson \& Neilson, 1976; Weiss,1978; Mössinger \& Barthold, 1987; Barthold \& Wenk, 1992.

Molinema dessetae (Bain, 1973) : Proechimys oris (Caviomorpha Echimyidae, natural host), peritoneal cavity, pleural cavity. Ref : Bain, 1973; Gayral et al., 1982; Gantier et al., 1987.

Monanema martini Bain, Bartlett, Petit, 1986 Lemniscomys striatus (Muridae, natural host), lymphatic vessels of the large intestinal wall, heart and pulmonary blood vessels. Ref : Wanji et al., 1990; Vuong et al., 1991.

Brugia malayi (Brug, 1927) : M. unguiculatus, peritoneal cavity and processus vaginalis, lymphatic system, heart and lungs. Ref : Buckley \& Edeson, 1956; Edeson \& Wharton, 1957, 1958; Edeson \& Buckley, 1959; Laing et al., 1961; Ash \& Riley, 1970b; Ash, 1971; El Bihari \& Ewert, 1971; Ewert \& El Bihari, 1971; Vincent, Frommes \& Ash, 1976.

B. pabangi (Buckley et Edeson,1956) : M. unguiculatus, similar to B. malayi. Ref : Schacher, 1962; Zaini et al., 1962; Ramachandran \& Pacheco, 1965; Ahmed, 1966; Schacher \& Sahyoun, 1967; Ash \& Riley, 1970a; Denham et al., 1972; Ah \& Thompson, 1973; Kowalski \& Ash, 1975; Vincent, Frommes \& Ash, 1976; Denham et al., 1984.

\section{INOCULATION OF RODENTS}

With the Brugia species, the procedures of inoculation were often special in order to favour the lymphatic system of the legs and the testicular region for the eventual localisation of the adults : larvae were inoculated in the inguinal region (Ash \& Riley, 1970a), or scrotal region, or into the dorsum of the hind foot (Denham et al., 1972), after several puncture wounds (Ewert, 1971). In our other experiments, all infective larvae (L3) were inoculated subcutaneously into the right lumbar area of rodents three to four week old. A single dose of 25 L3 or 200 L3, sometimes more, was administered (see Table I). Larvae were harvested in RPMI 1640 supplemented with $20 \%$ calf serum from the respective vectors Bdellonyssus bacoti, Ornitbodoros moubata, Aedes aegypti Gkep strain, Aedes aegypti Liverpool strain.

\section{NECROPSY OF RODENTS}

Necropsies were performed from 1-3 days post-inoculation (p.i.) to 20-30 days p.i., and occasionally later (Table I). The dissection medium was RPMI $+20 \%$ calf serum. Each rodent was killed, flayed and the superficial lymph-nodes were removed (they were localized after the studies of Wenk,
1967 and Ah \& Thompson, 1973). The body was cut transversely to separate the abdominal and thoracic regions; viscera were removed, then the internal lymph-nodes. All organs were teased and observed separately. To present the results, organs were grouped into 8 regions (see below), in order to facilitate the comparison between the filarial species.

1. Subcutaneous tissue (Sc) corresponded to the isolated skin which was scraped on its internal surface and immersed into dissection medium. 2. External lymphatic system (ExtLy) : under this group were placed the following lymph-nodes : subiliac, inguinal, popliteal, axillary, accessory-axillary, submaxillary, parotid. They were isolated in pairs with the lymph vessels and surrounding adipose tissue, and teased. 3. Skeletal muscles and aponeuroses (Mu) : the muscles with the carcass were teased and decanted. 4. Internal lymphatic system (IntLy) grouped together the following lymph-nodes: renal, cranial-lumbar and lumbar, iliac, sacral, cranial thoracic, thoracic, cervical. Clearly identified lymphatic vessels were removed with the lymphnodes. 5. Abdominal cavity (AC) : worms from this region were those recovered around the abdominal viscera, and during the teasing of the testicular and ovarian regions. Practically, the group consisted of worms free in the AC and those which were released from the lymph vessels during teasing. 6. Thoracic cavity (TC) : this grouped the pleural and pericardial cavities. 7. Heart (He) : the cardiac cavities were analyzed separately, after removal of the pericardium. 8. Lungs (Lu) : worms from this organ were those recovered after teasing. In fact the distinction between TC and $\mathrm{Lu}$ is not precise at the time of dissection due to the complex structure of the lungs as numerous folds of the visceral pleura are infiltrated between the ramifications of the pulmonary parenchyma.

The abdominal viscera (liver, kidney, digestive tract) did not show any worms and are not reported in Table I.

The filarial distribution in the different organs or tissue of a rodent was expressed in percentages of the total number of worms recovered per rodent (Table I). Filarial stages and molts were identified.

\section{HISTOLOGICAL TECHNIQUE AND FIXATION OF RODENT MATERIAL}

Some rodents inoculated with 200L3, or more, were fixed in toto for histopathological study (see technical procedures in Wanji et al., 1990 and Vuong et al., 1991). The number of rodents studied, the number of days p.i. (D) and the number of rodents for each time are listed. - L. sigmodontis : 7 jirds, D1x3, D3x2, D10x2, plus three thoracic regions fixed respectively at D1, 5 and 8 . - A. viteae : 14 jirds, D1x1, D2x2, D3x1, D5x2, D8x1, D12x2, D20x2, D30x2, D45x1. Mo. dessetae : 4 P. oris, D1*, D2*, D8*, D13 (*thoracic region not fixed). - M. martini : for details see Wanji et al. (1990) and Vuong et al. (1991). - Brugia malayi : 6 jirds, D1, D3, D5, D10, D17, D30. - B. pahangi : 2 jirds; these received three doses of larvae $(200 \mathrm{~L} 3+100 \mathrm{~L} 3+100 \mathrm{~L} 3)$ at one week intervals and were fixed 27 days after the first inoculation ( $=14$ days after the last inoculation).

Histological examination was made as defined in Vuong et al., 1991 : each block was sectionned; two serial sections per block were observed; the parasites and lesions were 
localized and the types of the inflammatory process were identified : - 1 : chronic non-specific inflammation; - 2 : acute inflammation; - 3 : sub-acute inflammation; - 4 : granulomatous inflammation; - 5: scarring fibrosis. The reactive lesions were further identified as: hyperplasia of the mono-histiocytic system, lymphoid hyperplasia, dilation of lymphatic vessels, mesothelium hyperplasia etc.

\section{STATISTICAL ANALYSIS}

To compare the percentages F/L3 in the different groups of rodents, and the percentages of filariae in different organs of rodents, two non-parametric tests were used: $\mathrm{U}$ test of Mann and Whitney and $H$ test of Kruskal-Wallis. Confidence interval to $95 \%$.

\section{RESULTS}

\section{I - QuANTITATIVE RELATIONSHIPS BETWEEN INOCU-} LATED LARVAE AND FILARIAE RECOVERED

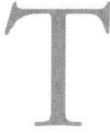

he percentages of inoculated larvae which developed (recovery rate F/L3) are presented in Table 1.

L. sigmodontis : in the 200 L3-inoculated rodents, $51.5 \%$ of larvae were recovered at D1 p.i.; later, the F/L3 percentage did not reduce: its mean values were $44.2 \pm 11.6 \%$ from D1 to D20 and $57.5 \pm 12 \%$ at D60 $(\mathrm{n}=14$ and 6 respectively). F/L3 values were similar in the rodents inoculated with 25 or $60 \mathrm{~L} 3$ (respectively 9 and 2 data). All results were similar and a mean value was calculated and found to be $48.1 \pm 14.6 \%$.

A. viteae : in rodents with 200 or $25 \mathrm{~L} 3$ ( $n=6$ per group), the percentages of filariae recovered were similar from D2-3 to D30-33, with a mean of $51.1 \pm 2.4 \%$.

Mo. dessetae: in the rodents inoculated with 200-380 L3 and dissected from D2 to D19, F/L3 varied more than in the two previous species but no reduction with time p.i. was noticeable; the mean was $3.1 \pm 3.1 \%(n=9)$. In the rodents inoculated with $\geq$ 1000 L3 and dissected from D1 to D11, F/L3 mean was $4.3 \pm 2.8(n=3)$. The difference between the two groups was not significant; the mean percentage of larvae which developed was $3.4 \pm 3 \%$.

M. martini : in rodents inoculated with 400,80 or 30 L3 (respectively $n=8,9$ and 12 ), the percentages of filariae recovered were similar from D2 to D180-240, with a mean of $46.3 \pm 5.9 \%$ (Wanji et al., 1990).

B. malayi : in the five $200 \mathrm{~L} 3$-inoculated rodents, F/L3 mean was $22.8 \pm 8.5 \%$ from D2 to D30.

B. pahangi: in the $200 \mathrm{~L}$-inoculated rodents, the percentages of filariae recovered were stable from D1 to $\mathrm{D} 22$, with a mean of $24.1 \pm 4.3 \%(\mathrm{n}=4)$; it was significantly lower at D27-30 with a mean of
$11.2 \pm 4.8 \%(n=5)$. In the $25 \mathrm{~L} 3$-inoculated rodents, $\mathrm{F} / \mathrm{L} 3$ remained at the same level from D1 to D30, with a mean of $24.5 \pm 5.8 \%$.

\section{II - Migrations}

A - Duration of migrations

L. sigmodontis : $70 \%$ of larvae had left the subcutaneous tissue after the first day; at D10, more than $60 \%$ of larvae were in the pleural cavity; they were young fourth stage larvae measuring $2000 \pm 240 \mu \mathrm{m}$ long and $40 \pm 5 \mu \mathrm{m}$ wide.

A. viteae: it was difficult to determine the duration of the migrations in this species which is mainly into the aponeuroses of the skeletal muscles, but at D12 p.i., deep larvae lining the abdominal cavity and larvae in the thoracic region were noted; these were young fourth stage larvae; one of them measured was 4.600 $\mu \mathrm{m}$ long and $60 \mu \mathrm{m}$ wide.

Mo. dessetae: worms stayed in the subcutaneous tissue several days and started migrating at D10, when the larvae were old third stages, or molting and measuring 1600/38 $\mu \mathrm{m}$, or young fourth stages.

M. martini : $30-40 \%$ of larvae had left the superficial tissues at D2 and almost all larvae at D5; worms reached the lymphatic vessels of the intestinal wall between D5 and D15; the third molt occurred at D10 from larvae 1420-1500/18-23 $\mu \mathrm{m}$.

B. malayi and B. pahangi : worm localisations were varied; a few stayed in the superficial lymphatic system but most of them migrated deeper; at D2, 70-80\% had reached the deep regions (internal lymphatic system, coelomic cavities, heart, lungs). The third molt was seen at D10 in rodents infected with B. malayi from a larva measuring 1950/30um.

\section{B - Distribution of filariae}

In the six species, filarial worms were found in the lymphatic system. The coelomic cavities and the heart-lung system were also often parasitized (Table I and II; Figs. 1, 2, 3).

a- The lymphatic system

L. sigmodontis : from D1 to D3, 50 \% of larvae were recovered from the inguinal, sub-iliac lymph-nodes but mainly from the lumbar lymph-nodes. The axillary and sub-axillary lymph-nodes were rarely parasitized. In histological sections, material from three of the rodents fixed at D1 and D3 showed this last pair of lymph-nodes to be infected with several larvae which were in the subcapsular sinus or in the afferent vessel (Fig. 1A).

A. viteae : one or two worms were recovered from lumbar lymph-nodes in three rodents, at D2, 12 and 


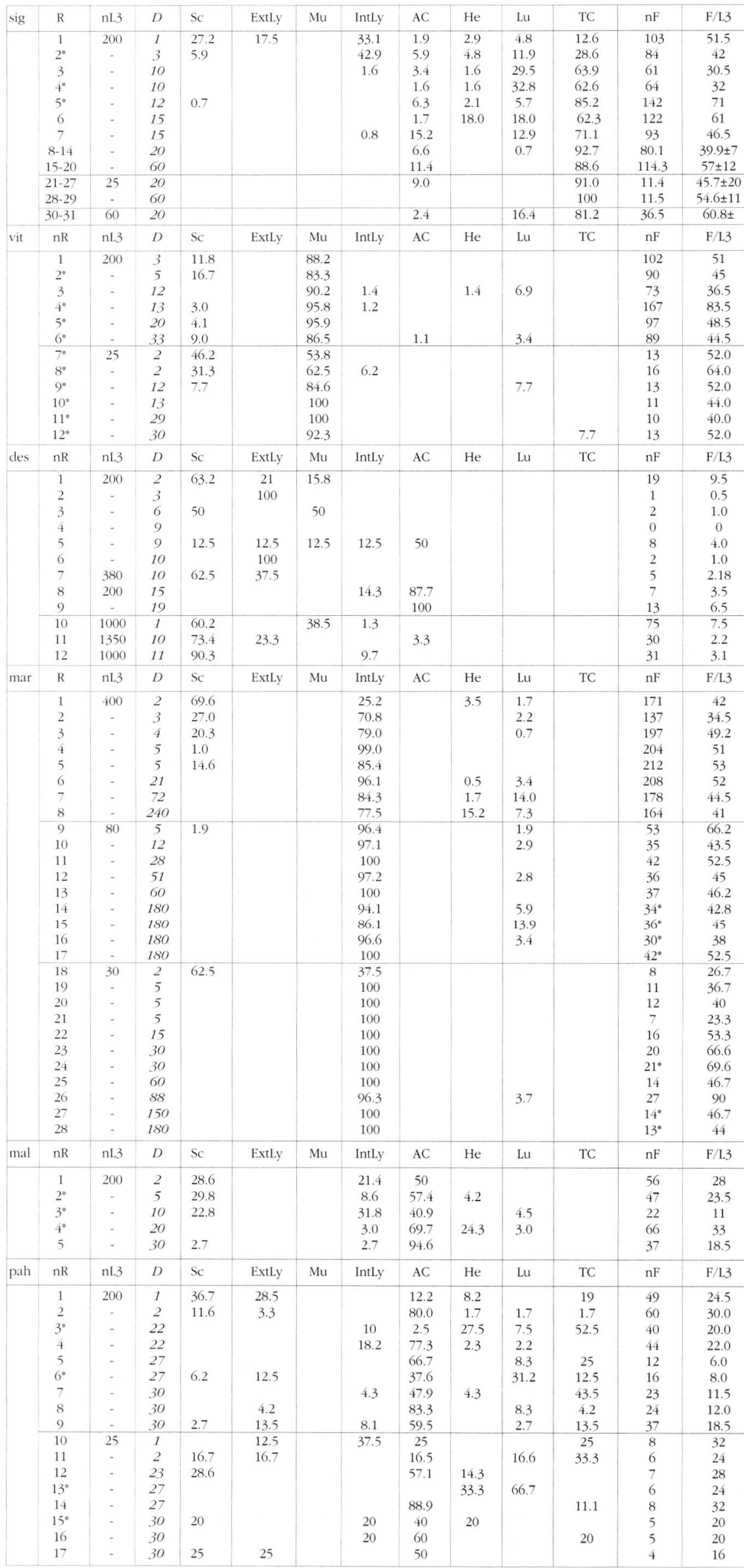

Table I. - Evolution of the distribution of six filarial species in the rodent and of the recovery rate: Litomosoides sigmodontis in Meriones unguiculatus (sig), Acanthocheilonema viteae in $M$. unguiculatus (vit), Molinema dessetae (des) in Proechimys oris, Monanema martini in Lemniscomys striatus (mar), Brugia malayi in $M$. unguiculatus (mal), B. pabangi in $M$. unguiculatus (pah).

$\underline{\mathrm{R}}$ : number of individual rodents $\left(^{*}=\right.$ female rodent). $\underline{\mathrm{nL} 3}$ : number of infective larvae inoculated. $\underline{D}$ : number of days between inoculation and necropsy. $\underline{\mathrm{Sc}}$ : subcutaneous tissue. ExtLy : external lymphatic system (inguinal, sub-iliac, popliteal, axillary and neck lymph-nodes, with associated lymphatic vessels). $\underline{\mathrm{Mu}}$ : skeletal muscles and aponeuroses. IntLy : internal lymphatic system (lumbar, iliac, mesenteric, sacral, thoracic lymph-nodes with associated lymphatic vessels including those from the testicular and ovarian regions). $\underline{\mathrm{AC}}$ : peritoneal and vagino-peritoneal cavities. He : right heart. Lu : lungs. TC : pleural and pericardial cavities. $\underline{\mathrm{nF}}$ : number of filariae recovered (* for $M$. martini, when the small intestine was not dissected, the value was corrected by adding 5\% to the amount of worms recovered). $\mathrm{F} / \mathrm{L} 3$ : percentage of infective larvae which developed. 
13. In sections, filarial worms were found in this lymph-node at D1, 5 and 20; larvae were in the subcapsular or cortico-medullary sinuses (Fig. 1C and D respectively) or in an afferent vessel. Worms were also found in the lymphatic vessel of the deep aponeuroses at D12, parietal mesentery at D12, 20 and 33 (Fig. $1 \mathrm{E}$ to $\mathrm{H}, 2 \mathrm{D}$ ) and pericardium at D20.

Mo. dessetae: worms were recovered in the external lymphatic system at D2, 3, 10, 11 with respectively 4 , 1,5 and 28 larvae, and in the lumbo-iliac lymphatic complex at D1, 9, 11 and 15 , with respectively 1, 1, 3 and 1 larvae. No worms were found in sections.

M. martini : from D2 to D5, numerous larvae were recovered from the renal and lumbar lymph-nodes; later they were recovered from the mesenteric and intestinal lymphatic vessels (Wanji et al., 1990). These localisations were confirmed in sections (Vuong et al., 1991).

B. malayi: 2 to $30 \%$ of filariae were seen in the lymphatic system (vessels and lymph-nodes) during the dissections; the lymph-nodes infected were varied, including the axillary and popliteal lymph-nodes. In sections, one larva was found in the subcapsular sinus of a lumbar lymph-node on D3, and 3 larvae in the sinus of an external regional lymph-node (subiliac or inguinal ?) and in its afferent vessel on D5 (Fig. 2 E, F, G) and in a lymphatic vessel of the lumbar region on D17 (Fig. $3 \mathrm{C}$ ).

B. pahangi : 0 to $37 \%$ of the filariae were recovered from the lymphatic system at dissection. In sections of the material from two fixed rodents, one worm was found in the lymphatic vessel of the adipose tissue associated to the testicules, five filariae were found in a lymphatic vessel close to an ovary.

b - Coelomic cavities

L. sigmodontis : the pleural cavity was the main localisation but some filariae were found in the peritoneal cavity : $5.1 \pm 4.8 \%$ from D1 to 15 and $8.8 \pm 15 \%$ from D20 to D60 in the $200 \mathrm{~L} 3$ inoculated rodents (no significant difference); in the $25 \mathrm{~L} 3$ inoculated rodents dissected from D20 to D60, the percentage was similar : $7 \pm 11$.8. In sections, one filaria was in the pe-ritoneal cavity on D20.

A. viteae: at dissection, one filaria was found on D3 in the peritoneal cavity and one on D33 in the thoracic cavity. In sections, one worm was in the pericardial cavity and one in the mesenteric cavity on D20, one or two worms in the pleural cavity twice on D30 and on D45 (Fig. 2 A, B, C).

Mo. dessetae : filariae were found in the peritoneal cavity at dissection only. The thoracic region was not fixed for histological study.
M. martini : no filariae were found in the coelomic cavities.

B. malayi : filariae were found in the peritoneal cavity (including the vagino-peritoneal cavity). In sections, one filaria was seen in the vagino-peritoneal cavity on D5 and one in the thoracic cavity on D17.

B. pahangi : filariae were more abundant in the peritoneal plus vagino-peritoneal cavities than in the pleural cavity, with similar proportions whatever the number of larvae inoculated: 51.9 and $19 \%$ respectively with 200 L3, 42.2 and $11.1 \%$ respectively with 25 L3. Male rodents had a significantly higher mean percentage of peritoneal filariae than female rodents $(65.2 \pm 14.2 \%$ and $20.0 \pm 21.7 \%$ respectively) over similar periods of observation ( $\geq$ D22).

c - Heart

L. sigmodontis : cardiac filariae were observed until D15; during that period 6 out of 7 rodents were parasitized. A mean percentage of $4.4 \%$ of the total filariae were found in the heart; male and female rodents were similarly parasitized with respectively 5.6 and $2.8 \%$ of the filariae found. In sections, one filaria was found in the right ventricle at D3.

A. viteae : at dissection, one rodent had a cardiac filaria at D12; no cardiac filariae was found in sections.

Mo. dessetae : no filariae were found in the heart on dissection; the thoracic region was not fixed for histological analysis.

M. martini : a mean of $0.3 \%$ of filariae was in the heart. In sections, filariae were found in the right ventricle (Wanji et al., 1990; Vuong et al., 1991).

B. malayi: in the five rodents dissected, the two males had no cardiac filariae; two of the females had filariae in the right ventricle at D5 and 20 (4.2 and 4. $3 \%)$. No filariae were found in sections.

B. pahangi : at D1 and 2, four male rodents were dissected and a mean of $2.2 \%$ of the total filariae was in the heart. From D22 to D30, four females and nine males were dissected and had respectively $20.0 \pm 14.5 \%$ and $2.3 \pm 4.7 \%$ cardiac filariae (significantly different). No filariae were found in sections.

d - Lungs

L. sigmodontis : pulmonary filariae were found in each rodent until D15, with a maximum of $30 \%$ at D10; male and female rodents were similarly parasitized with respectively 16.8 and $16.3 \%$. From D20 to D60 pulmonary filariae were rare. They were found in three rodents only among twenty-four dissected, with respectively 3,1 and 11 filariae, at D20. In sections, one filaria was found in a pulmonary artery in two rodents at D1 and in one rodent at D3; two filariae were also found in the pulmonary alveoli, respectively at D1 and D2 (Fig. 2). 

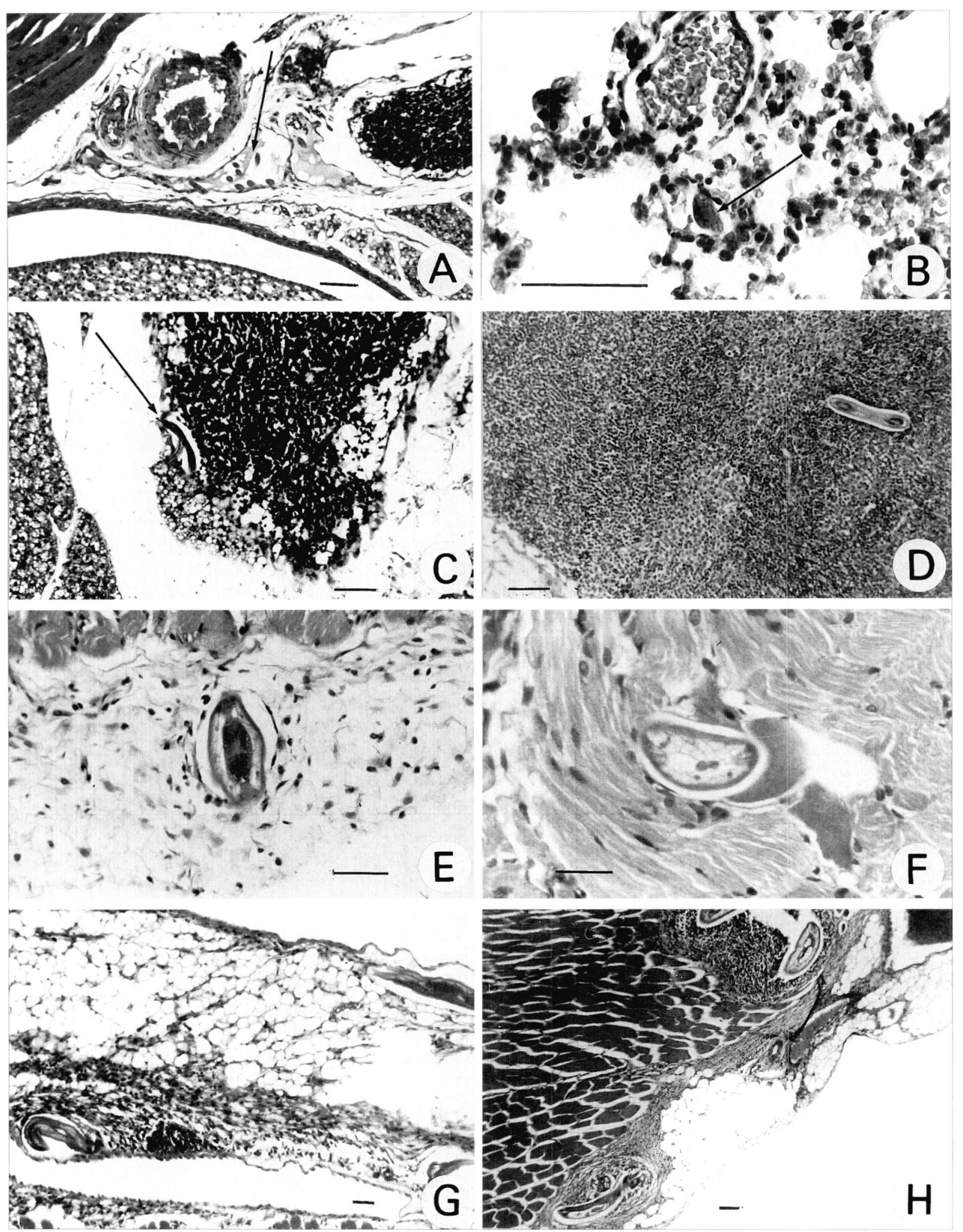

Fig.1. - L. sigmodontis, $\underline{\mathrm{A}}$ : larvae in a lymphatic vessel near the lumbar lymph-node, D1 p.i.; $\underline{B}$ : larva in a pulmonary alveole, associated with alveolitis, D1 p.i. A. viteae, $\underline{\mathrm{C}}$ : larva in the sub-capsular sinus of a lumbar lymph-node, D1 p.i; $\underline{\mathrm{D}}$ : larva in the cortico-medullar sinus of a lumbar lymph-node, D5 p.i; $\underline{\mathrm{E}}$ : larva in a lymphatic vessel of the parietal peritoneum, D12 p.i.; $\underline{\mathrm{F}}$ : larva in a lymphatic vessel of the aponeurosis of an abdominal muscle, with inflammatory lesion of type 2, D12 p.i.; $\underline{G}$ : two larvae in two lymphatic vessels of the parietal peritoneal chorion, with an inflammatory infiltration of type 3, D12 p.i.; $\underline{H}$ : in the aponeurosis and the parietal peritoneum, two filariae in two cavities surrounded by an inflammatory tissue of type 3, and type 5 at the periphery, which form two onchocercomata, D45 p.i. 


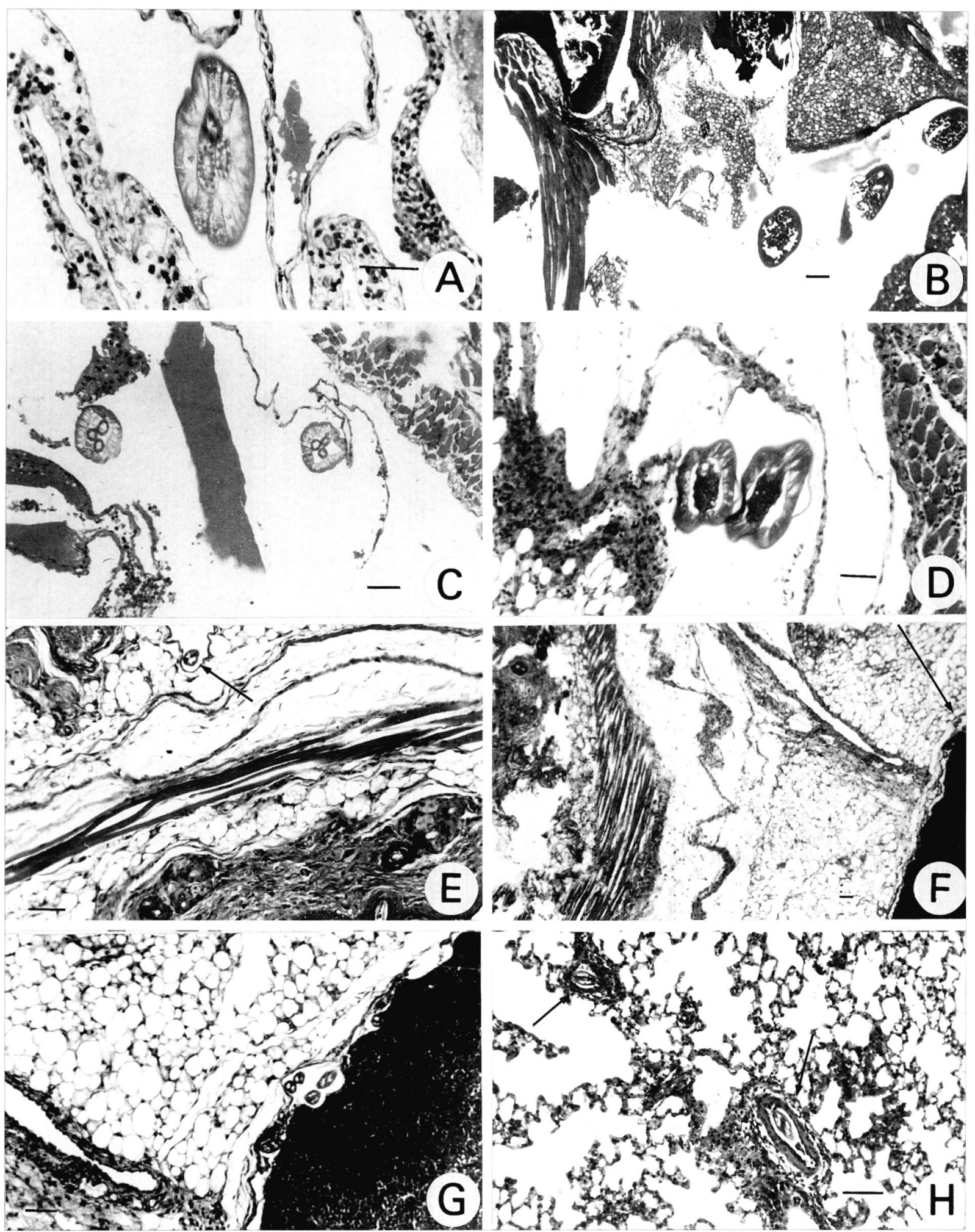

Fig. 2 - A. viteae, $\underline{\mathrm{A}}$ : larva in the pleural cavity, with inflammatory lesions of types 1, 2, 3, mesothelial hyperplasia and pleural exsudate, D 20 p.i.; $\underline{B}$ : filaria in the pleural cavity, D45 p.i.; $\underline{\mathrm{C}}$ : filaria in the peritoneal cavity, with mesothelial hyperplasia and ascitic exsudate, D20 p.i.; $\underline{\mathrm{D}}$ : filaria in a lymphatic vessel of the chorion of the parietal peritoneum, D45 p.i. B. malayi, $\underline{\mathrm{E}}$ : larva in a subcutaneous lymphatic vessel, D5 p.i.; $\underline{F}$ : larva in the subcapsular sinus of a subcutaneous lymph-node, D 3 p.i.; $\underline{G}$ : idem, detail; $\underline{H}$ : larva in a small pulmonary artery with arteritis, D5 p.i. (bar $=50 \mu \mathrm{m})$. 


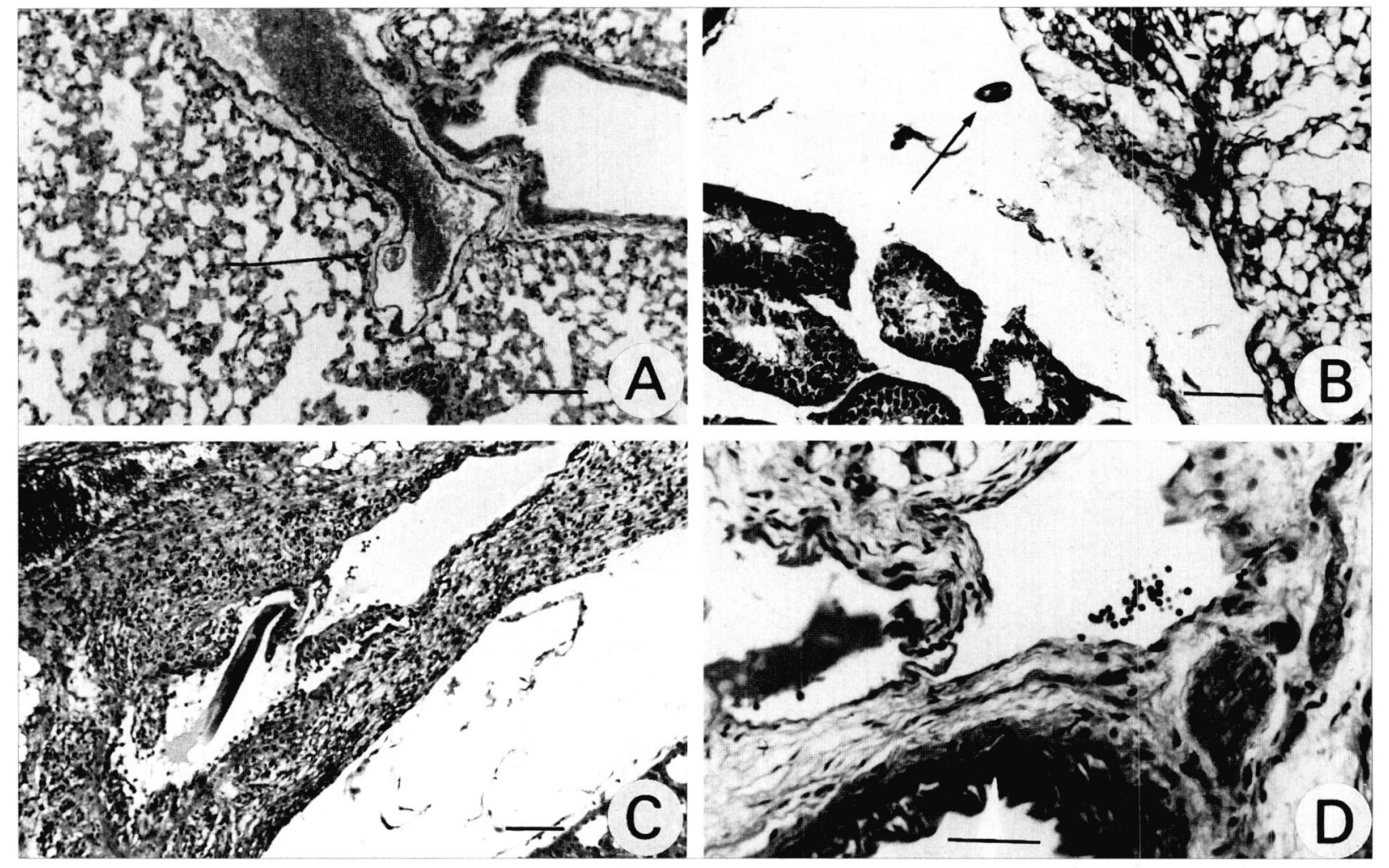

Fig. 3 - B. malayi,$\underline{A}$ : larva in a large pulmonary artery without lesion, D5 p.i.; $\underline{B}$ : larva in the vagino-peritoneal cavity, D5 p.i.; $\underline{C}:$ larva near the valvula of a lymphatic vessel of the lumbo-renal region, associated with lymphangitis and sclerosis, D. 17 p.i.; $\underline{D}$ : a lymphatic vessel offers a large natural path for migration (bar $=50 \mu \mathrm{m})$.

\begin{tabular}{|c|c|c|c|c|c|}
\hline Organ & sigmondontis & viteae & martini & malayi & pabangi \\
\hline Musc-apon-subcut & & $\mathrm{D} 2$ to $\mathrm{D} 45$ & D1 & & D13/27 \\
\hline Ext lymph syst & D1 & $\mathrm{D} 2-5-12-30-45^{*}$ & D1-5 & D5 & \\
\hline Int lymph syst & D1-3×2 & D1-5-12×2-20-30×2-45 & D2 to 20 & D3-5-24 & $\mathrm{D} 13 / 27 \times 2$ \\
\hline Abd. vag-perit cav & D20 & D30 & & D5-10 & \\
\hline Thoracic cav & D10 & D $20-30 \times 2-45$ & & D17 & \\
\hline Right heart & D3 & & & D17-24 & \\
\hline Pulm arteries & $\mathrm{D} 1 \times 2-3$ & & D $7-12-20$ & D5 & D13/27 \\
\hline Pulm alveoles & D1-2 & D30 & & & \\
\hline Veins & & & & & $\mathrm{D} 13 / 27 \times 2$ \\
\hline $\mathrm{n}$ rodents & 10 & 14 & 21 & 6 & 2 \\
\hline
\end{tabular}

Table II. - Localisation of filarial worms in histological sections.

Organ : see Table I. D : days between inoculation of infective larvae and fixation of the rodent; D1 $\times 2$ : two rodents fixed at D1 etc D13/27 : with B. pahangi, the two M. unguiculatus were inoculated three times at one week intervals and fixed 27 days after the first inoculation. $\mathrm{n}$ rodents : total number of rodents fixed. 
A. viteae: at dissection three rodents had one or two filariae in the lungs, at D12 two rodents, and D33 one rodent. In sections, one altered larva was found in a pulmonary alveolus at $\mathrm{D} 30$.

Mo. dessetae : no filariae were found in the lungs at dissection.

M. martini : a mean of $3.5 \%$ of filariae was in the lungs. In sections, filariae were found in the pulmonary arteries of several rodents (Wanji et al., 1990; Vuong et al., 1991).

B. malayi: the two males dissected had no pulmonary filariae; two of the three females had filariae in the lungs, at D10 and 20 (4.5 and $3.0 \%$ ). In sections, two filariae were found in the pulmonary arteries at D5 (Fig. 2 H, 3 A).

B. pahangi : at D1 and 2, the four male rodents dissected had a mean of $4.6 \%$ of pulmonary filariae. From D22 to D30, four females and nine males had respectively $26.3 \pm 30 \%$ and $2.4 \pm 3.5 \%$ of filariae in the lungs (difference almost significant). In sections, one filaria was in a pulmonary artery of a male rodent.

e - Other localizations

With B. pahangi, the sections of two rodents fixed for histological analysis showed filariae in large veins. In the female, three filariae were found in the inferior vena cava, at the kidney level. In the male four filariae were found in the portal vein of the liver. These rodents were inoculated three times, at one week intervals.

\section{C- Lesions}

The lesions were due, in the main, to the inflammatory process; reactive lesions were common.

a - Subcutaneous tissue: there were lesions in the connective tissue lining the subcutaneous muscle in the region of the inoculation of the infective larvae. These lesions evolved from acute type 2 in the first hours to sclerosis type 5 .

b - Muscles, aponeuroses: very intense lesions were observed with $A$. viteae, associated with most of the filariae seen. The lesions were type 2 , or types 2 and 3 , sometimes surrounded by type 5 ; filariae in these lesions were generally normal (Fig. $1 \mathrm{~F}, \mathrm{G}, \mathrm{H}$ ) and only a few were altered.

c - Lymphatic system : lesions of the lymphangitis type 2 and 3 might occur around a vessel containing a larva, whatever the filarial species. Frequently the lesion extended to the connective tissue surrounding the neighbouring blood vessels and this was particularly common in the lumbar region. In the case of $A$. viteae, lymphangitis of a lymphatic vessel of the apo- neurosis containing a worm was frequent, often very intense with erosion of the endothelium and infiltration of inflammatory cells into the vessel lumen, the whole resembling a pseudo-cyst (Fig.1 F, G, H). The parasitized lymph-nodes showed mild inflammatory lesions (types 2, 3 4); monohistiocytic hyperplasia and lymphoid hyperplasia were common and often intense.

d - Visceral peritoneum, mediastinum and pericardium: hyperplasia of the mesothelium was intense, associated with type 3 and 4 , when filariae were in the peritoneal or pleural cavities, or in the chorion (Fig. $2 \mathrm{~A}, \mathrm{C}$ ).

e - Heart : no lesion was observed, even when larvae were present in the cardiac cavity.

f - Lungs : inflammatory lesions in the parenchyma were not frequent and were associated with larvae : alveolitis was noted with $L$. sigmodontis and $A$. viteae, associated with small localysed hemorrhages in the case of the first species. Endarteritis was noted since day 20 with the two Brugia species. Major lesions (oedema, type 2 and 3 inflammatory lesions) occurred in the peripedicular visceral pleura with L. sigmodontis, from D5 to day 10, then regressed.

\section{DISCUSSION}

\section{ROUTES OF MIGRATIONS}

A common feature in the filariae studied is that the migrations occurred by the lymphatic route. This is true even among the filariae for which the final localisation is not lymphatic, as had been shown by Wenk (1967) with L. sigmodontis.

Our analyses concern the Onchocercinae but it seems probable that the intralymphatic migration is a more general phenomenon among filariae. It was demonstrated with a lizard filaria of the sub-family Oswaldofilariinae (Menon et al.,1944) and it seems that the data on the distribution of Dirofilaria immitis during its larval life (Kotani and Powers, 1982) fits quite well with the hypothesis of intralymphatic migration.

Onchocerca species have never been studied in this aspect but they do not seem different and this is strongly suggested by the histo-pathological analyses performed with these experimental filariae. In a lesion of lymphangitis of the vessels parasitized by larvae, the vascular endothelium may be eroded by the polymorphonuclear cells which then infiltrate into the vascular lumen (Vuong et al., 1991); the lymphatic vessel becomes no longer delimited and the lesion evokes the aspect of the onchocercal pseudo-cyst. 
This similarity, already noted by Vuong et al., (1993) with a sub-cutaneous filaria of the genus Cercopithifilaria, is reinforced by the numerous pictures shown on $A$. viteae in the muscular aponeuroses (Fig. 1F, G,H).

\section{Arrival in the coelomic cavities}

The filariae which are migrating through the lymphatic route either stay in the vessels ( $M$. martini) or escape from them more or less early. Mo. dessetae, a high proportion of Brugia spp. and a small proportion of $A$. viteae thus arrive in the peritoneal cavity (and maybe in the vagino-peritoneal cavity).

It is also by breaking the lymphatic vessels, but after a migration through the thoracic channel, that the filariae arrive in the pleural cavity. This localisation exists in all the filariae, even with Mo. dessetae according to Gantier (personal communication). It is only with $L$. sigmodontis that this localisation is predominant.

For this last species, Wenk (1967) had indicated that the larvae must pass through the cardio-pulmonary blood system to reach the pleural cavity. At a first glance, this fits with our results from the dissections which showed large amounts of pulmonary larvae (Table I); but, as it was underlined at the beginning of this work, the precise localisation of the filariae cannot be determined at necropsies because the visceral pleura adheres to the lungs. Such a migration seems impossible because it might provoke hemorrhages during the breaking of the pulmonary capillaries, and these are very rarely found in histological sections, as also are larvae in the pulmonary blood vessels.

\section{Arrival in the cardio-pulmonary blood system}

From our observations it seems that, in all the studied species, the vascular cardio-pulmonary localisations are accidental*. They appear as a consequence of the intra-lymphatic parasitism as this system connects with the blood system by the intermediary of the thoracic channel which emerges in the superior vena cava. Thus the filariae which are in the lymph-nodes and lymphatic vessels of the abdominal region may arrive by this route in the right auricle, the right ventricle, then the pulmonary arteries.

The adult filariae are capable of the same migration, as was shown with $M$. martini. The percentage of cardio-pulmonary filariae increased with time, it may also increase after drug treatments by macrofilaricides because the altered filariae are no longer able to

\footnotetext{
* Our numbers indicate for B. pahangi a concentration of parasites in these organs in the female jirds, as noticed by Ash (1971). But, when larger samples were used, the differences between female and male jirds were not confirmed (Ah \& Thompson,1973; Denham et al., 1984). This last result is in accordance with the anatomy of the lymphatic system, which is similar in both sexes (Ah \& Thompson,1973).
}

maintain themselves in place, and they are passively drawn back with the lymph flow (Wanji et al., 1994; Bain et al.,1994).

It appears that the particular case of the true vascular cardio-pulmonary filariae (such as D. immitis) is the result of a secondary adaptation. Their localisation is achieved in the same way as in other species; that is after a lymphatic migration (and not by direct penetration through the myocardium, as it has been suggested). The fact that Kotani and Powers (1982) recovered $87 \%$ of the $D$. immitis larvae from the abdomen, at D21 p.i., before finding them in the thorax, fits in with all our results.

The presence of parasites in the lymphatic system and in the cardio-pulmonary blood system induces stasis. The parasites may provoke a pushing back of larvae when these reach the superior vena cava; this seems to explain the presence of $B$. pabang $i$ in the large veins of the trunk in jirds inoculated with a total of $400 \mathrm{~L} 3$, three times.

\section{RECOVERY RATE AND HOST DEFENCES}

In the evolution of the worm recovery we were able to distinguish three phases.

\section{Phase 1 of massive destruction of larvae}

A great number of larvae were destroyed immediately at the site of inoculation. Generally these larvae were not observed at dissection though they were observed with Mo. dessetae, because it was possible to inoculate a thousand larvae and because mortality was very high (96\%).

The proportion of filariae eliminated, which was similar when either a small dose or a large dose of larvae was inoculated (Table I), was characterisitic of the filaria-host pair and it corresponded to the proportion of larvae which were able to penetrate into the subcutaneous lymphatic vessels.

\section{Phase 2 of insignificant mortality}

During the following days, the recovery rate remained almost stable whatever the dose inoculated (Table I : F/L3). The larvae were in a medium (lymph) only moderately agressive, several of the elements of the inflammatory process were absent [platelets, polymorphonuclear cells, the complement system, factor XII (Diebold et al., 1987)]. In the coelomic cavities, only some mononuclear cells which had escaped from the chorion of the serosa were present (see Greep \& Weiss, 1973). This could explain several features already established such as the better development of larvae in white mice when they are inoculated intraperitoneally (Howells et al., 1983) and the larger size of $A$. viteae in the peritoneal cavity (Mössinger \& Barthold, 1987). 
Furthermore the larvae have two means of protection: they molt at 8-10 days p.i., whatever the species, clearing themselves of the highly antigenic cuticle elaborated during their life in the vector (molt 3 ) and as they are very motile in the lymphatic vessels they may leave behind this cuticle and escape the inflammatory reaction by moving forward towards new regions of the host; in the cases in which data were easy to determine (M. martini and Mo. desseteae), it was noted that larvae reached their definitive localisation after the third molt.

The phase 2 during which the mortality of filariae is insignificant has a duration characteristic of the filariahost pair. It lasts at least one month with $A$. viteae, B. malayi and B. pahangi (when the inoculate is 25 L3), at least two months with L. sigmodontis, six months with Mo. dessetae [recovery rate of $6 \%$ at the sixth month (Gayral et al., 1982)] and finally eight months with M. martini (Wanji et al., 1990). It should be noted that, in all the cases analyzed, this duration is longer than the time of emergence of a specific immune response (one week to activate the T lymphocytes; two weeks for the B cells to produce antibodies).

The absence of regulation which characterises this period is also demonstrated by the distribution of filariae as for any given species, worms were distributed according to constant proportions in the different organs

\section{Phase 3 of regulation}

The protection in the lymphatic vessels and the coelomic cavities is, of course, not total. With M. martini, the mesenteric lymphatic vessels parasitized by filarial larvae sometimes show lesions of lymphangitis and thrombolymphangitis (Vuong et al., 1991). Similar observations have been made with $B$. malayi in $M$. unguiculatus (Fig. 3C) and by Schacher and Sahyoun (1967) with B. pahangi in dogs. In the coelomic cavities, mesothelial hyperplasia associated with inflammatory lesions of the chorion is frequent (Fig. 2 A; and Gantier et al., 1987).

In the cardio-pulmonary blood system, the filariae in the arteries induce important reactions, e.g. endarteritis, inflammatory lesions of the parenchyma as described in detail for Brugia spp. by Vincent et al. (1976). The larvae which reach the pulmonary alveoli are doomed to destruction.

It is the phase 3 with regulatory phenomena which have been most commonly cited (Dhar \& Singha, 1971; Neilson \& Forrester, 1975; Weiss, 1978; Barthold \& Wenk, 1992; Wenk \& Mössinger, 1991; Table III).
In our experiments, the phase 3 was indicated only with B. pahang $i$ : when 200 L3 were inoculated, the percentage $\mathrm{F} / \mathrm{L} 3$ was decreasing at the third week, but it did not decrease when $25 \mathrm{~L} 3$ were inoculated (our numbers are statistically significant, but other experiments are in hand to verify the reliability of this case of early regulation).

With A. viteae and L. sigmodontis, the data published on times p.i. later than ours show the existence of this phases of regulation (Table III) but it does not appear early (Table I); for example, in $A$. viteae $-M$. unguiculatus, four months after the inoculation the ratio $\mathrm{F} / \mathrm{L} 3$ is $64 \%$ or $22 \%$ respectively with 5 or 90 larvae inoculated (Barthold \& Wenk,1992). It should be noted that these two filarial species induce in their experimental hosts notable inflammatory reactions, associated with, in the case of $L$. sigmodontis, an extremely intense mesothelial hyperplasia.

On the contrary, with M. martini - Lemniscomys striatus, no regulation was demonstrated. With this species, the adult filariae seem virtually to induce no reaction in the lymphatic vessels in which they live, slightly motile and spirally coiled, and their longevity is therefore considerable.

The phase 3 of regulation might be explained by the fact that when the number of filariae increases, the amount of antigens delivered when they die increases and thus the host response becomes more intense, resulting in an acceleration of the destruction of the filariae.

\section{CONCLUSION}

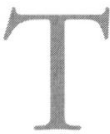
he six filarial species studied are very different in their localisations; nevertheless their larval biology presents some common features which appear fundamental.

1. - The destruction of the infective larvae occurs during the first $24 \mathrm{~h}$ following the inoculation, when they are in the sub-cutaneous tissue (phase 1). The proportion of larvae which survive corresponds to those which shelter in the lymphatic vessels where they are protected against polymorphonuclear cells, platelets etc. This ability to penetrate the lymphatics is not dependent upon the number of larvae inoculated and is characteristic of the filaria-host pair.

2. - Then the filarial mortality becomes insignificant (phase 2) and, if worm regulations appear, it is later (phase 3). This is because on one hand, molts, principally the third one, clear the filaria of the cuticle elaborated during the life in the vector; and, on the other hand, the filaria escapes the inflammatory process against foreign bodies in various ways : 
BAIN O., WANII S., VUONG P. N., MARÉCHAL P., LE GOFF L. and PETIT G.

\begin{tabular}{|c|c|c|c|c|}
\hline filaria & host & $\mathrm{nL} 3$ & $\mathrm{~F} / \mathrm{L} 3$ & authors \\
\hline \multirow[t]{2}{*}{ L. sigmodontis } & R. norvegicus & $\begin{array}{c}10^{*} \\
100^{*} \\
1000^{*}\end{array}$ & $\begin{array}{c}64 \\
34.5 \\
17.5\end{array}$ & $\begin{array}{c}\text { Dhar \& Singha, } \\
1971\end{array}$ \\
\hline & S. hispidus & $\begin{array}{c}5 \\
15\end{array}$ & $\begin{array}{l}43 \\
30\end{array}$ & $\begin{array}{c}\text { Wenk \& Mössinger, } \\
1991\end{array}$ \\
\hline M. martini & L. striatus & $\begin{array}{c}30 \\
80 \\
400\end{array}$ & $\begin{array}{l}47.3 \\
49.6 \\
45.8\end{array}$ & $\begin{array}{l}\text { Wanji et al., } \\
1990\end{array}$ \\
\hline M. globulosa & M. unguiculatus & $28-50$ & 0 to 50 & Bianco et al., 1983 \\
\hline \multirow{3}{*}{ B. pahang $i$} & F. catus & $\begin{array}{l}100 \\
200\end{array}$ & $\begin{array}{l}12.7 \\
7.8\end{array}$ & $\begin{array}{c}\text { Denham et al., } \\
1972\end{array}$ \\
\hline & M. unguiculatus & $\begin{array}{c}10-12 \\
20-40 \\
71-75 \\
85 \text { to } 100\end{array}$ & $\begin{array}{l}8 \text { to } 20 \\
7 \text { to } 20 \\
3 \text { to } 28 \\
3 \text { to } 21\end{array}$ & $\begin{array}{c}\text { Ash \& Riley, } \\
1970 \text { a }\end{array}$ \\
\hline & M. unguiculatus & $\begin{array}{l}75 \\
25\end{array}$ & $\begin{array}{l}15.5 \\
15.2\end{array}$ & $\begin{array}{c}\text { Kowalski \& Ash, } \\
1975\end{array}$ \\
\hline B. malayi & M. unguiculatus & $\begin{array}{l}45-56 \\
72-78\end{array}$ & $\begin{array}{l}11 \text { to } 16 \\
1 \text { to } 28\end{array}$ & $\begin{array}{l}\text { Ash \& Riley, } \\
\text { 1970b }\end{array}$ \\
\hline \multirow{3}{*}{ A. viteae } & C. auratus LAKZ & $\begin{array}{l}100 \\
150 \\
300\end{array}$ & $\begin{array}{l}44 \pm 7 \\
39 \pm 7 \\
23 \pm 8\end{array}$ & $\begin{array}{l}\text { Weiss, } \\
1978\end{array}$ \\
\hline & C. auratus & $\begin{array}{l}100 \\
200\end{array}$ & $\begin{array}{l}32 \\
30\end{array}$ & $\begin{array}{c}\text { Neilson \& Forrester, } \\
1975\end{array}$ \\
\hline & M. unguiculatus & $\begin{array}{c}5 \\
15-30 \\
60 \\
90\end{array}$ & $\begin{array}{l}64 \\
57 \\
38 \\
22\end{array}$ & $\begin{array}{l}\text { Barthold \& Wenk, } \\
1992\end{array}$ \\
\hline D. immitis & Mu.putorius & $\begin{array}{c}14 \\
280\end{array}$ & $\begin{array}{l}22.6 \\
39.5\end{array}$ & $\begin{array}{c}\text { Campbell \& Blair, } \\
1978\end{array}$ \\
\hline
\end{tabular}

Table III. - Principal published data on the relationships between inoculated larvae (nL3) and recovery rate (F/L3).

R : Rattus; S : Sigmodon; F : Felix; C : Cricetus.

a) Immobile maintenance in a lymphatic vessel: type M. martini.

b) Organisation in its lymphatic localization of a survival through a sclerosis resulting in the formation of a semi-permeable pseudo-cyst : type nodular Onchocerca species and A. viteae.

c) Flight from the lymphatic vessel into the coelomic cavity (abdominal or pleural) where, until it does not induce an inflammatory process, it is sheltered, not only from the polymorphonuclear cells and platelets but also from lymphocytes. The localizations of some Dirofilariinae (Pelecitus, see Bartlett, 1984) and Onchocerca sp. (see Popescu-Baran, 1939) in the joint-cavities, which are devoid of inflammatory cells, are similarly explained.

All our observations show that there is no clear cut differentiation between lymphatic and non lymphatic filariae; all filariae are lymphatic, in variable proportion, at some time in their life. The localisation in the cardio-pulmonary blood system appears accidental: during the course of migrating within lymphatic vessels when some larvae or adult filariae may penetrate into the thoracic channel and thus inevitably arrive into the superior vena cava. The risk of doing so is increased by antifilarial drugs, when the altered para- sites can no longer resist the centripetal lymph flow (Wanji et al., 1994; Bain et al., 1994).

We may expect similar events in human filariases; the few observations which have been done in humans confirm these features (Beaver et al., 1971; Beaver \& Cran, 1974); but they give no idea of the real frequency of these "aberrant" localisations of filariae, which are commonly underestimated. These "occult" filariae, lymphatic, coelomic and cardio-pulmonary, influence the immunological status of the host and thus the pathology, so filariases appear as generalised diseases.

\section{ACKNOWLEDGMENTS}

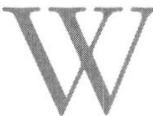
e are very grateful to Pr $\mathrm{H}$. Zahner for providing the two Brugia strains, to $\mathrm{Pr} \mathrm{H}$. Schulz-Key for providing the A. viteae strain, and to Pr R.S. Bray for revising the English.

\section{REFERENCES}

AH H.S. and Thompson P.E. : Brugia pahangi: infections and their effect on the lymphatic system of mongolian 
jirds (Meriones unguiculatus). Experimental Parasitology, 1973, 34, 393-411.

AHMED S.S.: Location of developing and adult worms of Brugia sp. in naturally and experimentally infected animals. Journal of Tropical Medicine and Hygiene, 1966, 69, 291-293.

Anderson R. C. and BAIN O. : Key to genera of the order Spirurida. Part 3. Diplotriaenoidea, Aproctoidea and Filarioidea, C. I. H. Keys to the Nematode parasites of Vertebrates. 1976, $\mathrm{n}^{\circ}$ 3, 59-116. Ed. R.C. Anderson, A.G. Chabaud \& S. Willmott.

Ash L.R. and Riley J.M. : Development of Brugia pabangi in the jird, Meriones unguiculatus, with notes on infections in others rodents. Journal of Parasitology, 1970a, 56, 962-968.

Ash L.R. and Riley J.M. : Development of subperiodic Brugia malayi in the jird, Meriones unguiculatus, with notes on infections in others rodents. Journal of Parasitology, 1970b, 56, 969-973.

AsH L.R. : Preferential susceptibility of male jirds (Meriones unguiculatus) to infection with Brugia pahangi. Journal of Parasitology, 1971, 57, 777-780.

BaIN O. : Une nouvelle filaire de rongeur sud-americain: Dipetalonema dessetae n. sp. (Nematoda, Filarioidea). Bulletin du Museum national d'Histoire naturelle, 1973 , 3e sér., n 116, Zool. 90, 309-316.

Bain O., Wanji S., Vuong P.N., Petit G., Breton B. and GANTIER J.C. : Cardio-pulmonary location of lymphatic filariae. Progress in Lymphology, Proceedings of the 14th International Congress of Lymphology, Sept. 20-26, 1993, Witte M.H., Witte C.L. (Eds.), The Intern. Soc. Lymphol., Zürich, Switzerland and Tucson, Arizona, 1994.

Baltazard M., Chabaud A.G. et Minou A. : Cycle évolutif d'une filaire parasite de mérion. Comptes rendus de l'Académie des Sciences de Paris, 1952, 234, 2115-2117.

Bartlett C.M. : Pathology and epizootiology of Dirofilaria scapiceps (Leidy, 1886) (Nematoda: Filarioidea) in Sylvilagus floridanus (J.A. Allen) and Lepus americanus Erxleben. Journal of Wildlife Diseases, 1984, 20, 197-206.

Barthold E. and Wenk P.: Dose-dependent recovery of adult Acanthocheilonema viteae (Nematoda : Filarioidea) after single and trickle inoculations in jirds. Parasitology Research, 1992, 78, 229-234.

Beaver P.C., Fallon M. and Smith G.H. : Pulmonary nodule caused by a living Brugia malayi-like filaria in an artery. American Journal of Tropical Medicine and Hygiene, 1971, 20, 661-666.

Beaver P.C. and Cran I.R. : Wuchereria-like filaria in an artery, associated with pulmonary infarction. American Journal of Tropical Medicine and Hygiene, 1974, 23, 869-876.

Bertram D.S. : Dynamics of parasitic equilibrium in cotton rat filariasis. Advances in Parasitology, 1966, 4, 255-319.

Bianco A.E, Muller R. and Nelson G.S. : Biology of Monanema globulosa, a rodent filaria with skin-dwelling microfilariae. Journal of Helminthology, 1983, 57, 259-278.

BuCKLEY J.J.C. and EDESON J.F.B. : On the adult morphology of Wuchereria sp. (malayi ?) from a monkey (Macaca irus) and from cats in Malaya, and on Wuchereria pabangi n.sp. from a dog and a cat. Journal of Helminthology, 1956, 30, 1-20.

Campbell W.C. and Blair L.S. : Dirofilaria immitis : experimental infections in the ferret (Mustela putorius furo). Journal of Parasitology, 1978, 64, 119-122.

Chabaud A.G. : Sur le cycle évolutif des Spirurides et des Nématodes ayant une biologie comparable. Valeur systématique des caractères biologiques. Annales de Parasitologie Humaine et Comparée, 1954, 29, 42-88, 206-249, 358-425.

Cross J.B. and ScotT J.A. : The developmental anatomy of the fourth stage larvae and adults of Litomosoides carinii, a filarial parasite of the cotton rat. Transactions of the American Microscopic Society, 1947, 66, 1-21.

Deibold J., Camilleri J.P., Reynes M. et Callard P. : Anatomie pathologique générale. J.B. Baillière EM Inter Ed. Med. Intern., Paris, 1987, 2nd ed., 331 p.

Denham D.A., Ponnudurai T., Nelson G.S. and Frances G., Rogers R. : Studies of Brugia pahangi-I. Parasitological observations on primary infections of cats (Felis catus). International Journal for Parasitology, 1972, 2, 239-247.

Denham D.A. and McGreevy P.B. : Brugian filariasis : epidemiological and experimental studies. Advances in Parasitology, 1977, 15, 243-309.

Denham D.A., Suswillo R.R. and Chusattayanond W. : Parasitological observations on Meriones unguiculatus singly or multiply infected with Brugia pahangi. Parasitology, 1984, 88, 295-301.

Dhar D.N. and Singha P. : Studies on quantitative infections of Litomosoides carinii (Travassos, 1919) in white rats. Zeitschrift für Tropenmedizin und Parasitologie, 1971, 22, 312-325.

Edeson J.F.B. and Buckley J.J.C. : Studies on filariasis in Malaya : On the migration and rate of growth of Wuchereria malayi in experimentally infected cats. Annals of Tropical Medicine and Parasitology, 1959, 53, 113-119.

Edeson J.F.B. and WharTon R.H. : The transmission of Wuchereria malayi from man to the domestic cat. Transactions of the Royal Society of Tropical Medicine and Hygiene, 1957, 51, 366-370.

Edeson J.F.B. and Wharton R.H. : The experimental transmission of Wuchereria malayi from man to various animals in Malaya. Transactions of the Royal Society of Tropical Medicine and Hygiene, 1958, 52, 25-45.

El Bihari S. and Ewert A. : Distribution of developing and mature Brugia malayi in rhesus monkeys and in the jird, Meriones unguiculatus, after a single infection. Journal of Parasitology, 1971, 57, 1170-1174.

Ewert A. and El Bihari S.: Rapid recovery of Brugia malayi larvae following experimental infections of cats. Transactions of the Royal Society of Tropical Medicine and Hygiene, 1971, 65, 364-368.

EWERT A. : Distribution of developing and mature Brugia malayi in cats at various times after a single inoculation. Journal of Parasitology, 1971, 57, 1039-1042. 
Gayral P., Dreyfuss G. et Gantier J.C. : Dipetalonema dessetae chez Proechimys oris : Cycle biologique de la filaire et proposition d'un modèle de filariose expérimentale de rongeur. Cabiers ORSTOM, Série Entomologie médicale et Parasitologie, 1982, 20, 81-94.

Gantier J.C., Maccario J., Vuong N.P., Gueyouche C. et GAYRaL PH. : Un nouveau modèle d'étude de la physiologie filarienne: Molinema dessetae chez son hôte définitif naturel Proechimys oris. Annales de Parasitologie Humaine et Comparée, 1987, 62, 241-261, 301-325.

GreEP R.O. and Weiss L. : Histology. McGraw-Hill Book, a Blakiston Publication, New York, Von Hoffman Press. Inc, $3^{\text {rd }}$ ed.,1973, $890 \mathrm{p}$.

Johnson M.H., Orihel T.C. and Beaver P.C. : Dipetalonema viteae in the experimental infected jird, Meriones unguiculatus. I. Insemination, development from egg to microfilaria, reinsemination and longevity of mated and unmated worms. Journal of Parasitology, 1974, 60, 302-309.

Howells R.E., Devaney E., Smith G. and Hedges T. : The susceptibility of $\mathrm{BALB} / \mathrm{C}$ and other inbred mouse strains to Brugia pahangi. Acta tropica, 1983, 40, 341-350.

Kershaw W.E. : The early migration-rate of the infective larva of Litomosoides carinii in the cotton rat. Annals of Tropical Medicine and Parasitology, 1953, 47, 68-73.

Kotani T. and Powers K.G. : Developmental stages of Dirofilaria immitis in the dog. American Journal of Veterinary Research, 1982, 43, 2199-2206.

KOwALSKI J.C. and AsH L.R. : Repeated infections of Brugia pahangi in the jird, Meriones unguiculatus. Southeast Asian Journal of Tropical Medicine and Public Health, 1975, 6, 195-198.

Laing A.B.G., Edeson J.F.B. and Wharton R.H. : Studies on filariasis in Malaya : further experiments on the transmission of Brugia malayi and Wuchereria bancrofti. Annals of Tropical Medicine of Parasitology, 1961, 55, 86-92..

Menon T.B., Ramamurti B. and Rao D.S. : Lizard filariasis. An experimental study. Transactions of the Royal Society of Tropical Medicine and Hygiene, 1944, 37, 373-386.

Mössinger J. and Barthold E.: Fecundity and localization of Dipetalonema viteae (Nematoda, Filarioidea) in the jird Meriones unguiculatus. Parasitology Research, 1987, 74, 84-87.

NeILson J.T.M. and Forrester D.J. : Dipetalonema vitae : primary, secondary and tertiary infections in hamsters. Experimental Parasitology, 1975, 37, 367-372.

POPESCU-BARAN M. : Nouvelles recherches sur l'Onchocerca bovis chez les Bovidés de France. Localisations synoviales. Bulletin de la Société de Pathologie Exotique, 1939, 32, 621-625.

Ramachandran C.P. and Pacheco G. : American cotton rat (Sigmodon hispidus) as an experimental host for Brugia pahangi. Journal of Parasitology, 1965, 51, 722-726.

SCHACHer J.F. : Developmental stages of Brugia pahangi in the final host. Journal of Parasitology, 1962, 48, 693-706.

Schacher J.F. and SAHYOUN P.F. : A chronological study of the histopathology of filarial disease in cats and dogs caused by Brugia pahangi (Buckley and Edeson, 1956).
Transactions of the Royal Society of Tropical Medicine and Hygiene, 1967, 61, 234-243.

ScotT J.A. : Observations on the rate of growth and maturity of Litomosoides carinii, a filarial worm of the cotton rat. Journal of Parasitology, 1946, 32, 570-573.

SCOTt J.A. and MacDonald E.M. : Experimental filarial infections in cotton rats. Experimental Parasitology, 1953, 2, 129-140.

Simpson C.F. and NeIlson J.T.M. : The pathology associated with single and quadruple infections of hamsters with Dipetalonema viteae. Tropenmedizin und Parasitologie, 1976, 27, 349-354.

Vincent A.L., Frommes S.P. and Ash L.R. : Brugia malayi, Brugia pahangi, and Brugia patei : pulmonary pathology in jirds, Meriones unguiculatus. Experimental Parasitology, 1976, 40, 330-354.

Vuong P.N., Wanji S., Sakka L., Klager S. and Bain O. : The murid filaria Monanema martini : a model for onchocerciasis. Part I : Description of lesions. Annales de Parasitologie Humaine et Comparée, 1991, 66, 109-120.

Vuong P.N., Spratt D., Wanji S., Aimard L. and Bain O. : Onchocerca-like lesions induced by the filarioid nematode Cercopithifilaria johnstoni in its natural hosts and in the laboratory rat. Annales de Parasitologie Humaine et Comparée, 1993, 68, 176-181.

Wanj S., Cabaret J., Gantier J.C., Bonnand N. and Bain O. : The fate of the filaria Monanema martini in two rodent hosts : recovery rate, migration and localization. Annales de Parasitologie Humaine et Comparée, 1990, 65, 80-88.

Wanj S., Vuong P.N., Gantier J.C., Bougnoux M.E., Breton B. and BaIN O. : Drug trials with Monanema martini : effect on the adult worms, the dermal microfilariae and the natural murid host. Parasite, 1994, 1, Suppl., 33-35.

Weiss N. : Studies on Dipetalonema vitae (Filarioidea). I Microfilaraemia in hamsters in relation to worm burden and humoral immune response. Acta tropica, 1978, 35. $137-150$.

Weinstein P.P. and Highman B. : Infection of the jird, Meriones unguiculatus, with the filarial worm, Dipetalonema viteae : central nervous system invasion and pathology. Journal of Parasitology, 1974, 60, 138148 .

WENK P. : Der Invasionsweg der metazyklischen Larven von Litomosoides carinii Chandler 1931. Zeitschrift für Parasitenkunde, 1967, 28, 240-263.

Wenk P. and Mössinger J. : Recovery of adult stages and microfilaremia after low dose inoculation of third stage larvae of Litomosoides carinii in Sigmodontes hispidus. Journal of Helminthology, 1991, 65, 219-225.

Zaini M.A., Ramachandran C and Edeson J.F.B. : Brugia species in the heart of hamsters. Transactions of the Royal Society of Tropical Medicine and Hygiene, 1962, 56, 6-7.

Accepté le 15 juin 1994 